\title{
A SECUNDARIZAÇÃO DA EDUCAÇÃO FÍSICA NA REFORMA DO ENSINO MÉDIO
}

\author{
SECONDARIZACIÓN DE LA EDUCACIÓN FÍSICA EN LA REFORMA DE LA ESCUELA \\ SECUNDARIA
}

\section{SECONDARIZATION OF PHYSICAL EDUCATION IN THE REFORM OF HIGH SCHOOL}

DOI: http://dx.doi.org/10.9771/gmed.v12i1.36

\author{
Gabriel Vielmo Gomes ${ }^{1}$ \\ Maristela da Silva Souza ${ }^{2}$
}

\begin{abstract}
Resumo: O presente estudo objetiva analisar os impactos da Lei 13.415 e da Base Nacional Comum Curricular para o ensino público da Cultura Corporal. Sob a luz do Materialismo Histórico Dialético, realizamos o diálogo entre a conjuntura política e educacional e a Educação Física, relacionando-as com a organização/reorganização do capital. Constatamos que as reformas educacionais direcionam novamente a escola para atender as demandas do mercado produtivo, e coloca a Educação Física na área das Linguagens, que resulta na perda de sua verdadeira identidade e de seu verdadeiro objeto de estudo, a Cultura Corporal, alterando assim, seu papel pedagógico no ambiente escolar.
\end{abstract}

Palavras-chave: Educação; Educação Física; Políticas Públicas; Reformas Educacionais;

Resumen: Este estudio tiene como objetivo analizar los impactos de la Ley 13.415 y la Base Curricular Nacional Común para la enseñanza pública de la Cultura Corporal. A la luz del materialismo dialéctico histórico, llevamos a cabo el diálogo entre la coyuntura política y educativa y la educación física, relacionándolas con la organización/reorganización del capital. Descubrimos que las reformas educativas nuevamente dirigen a la escuela a satisfacer las demandas del mercado productivo y ubican la Educación Física en el área de Idiomas, lo que resulta en la pérdida de su verdadera identidad y su verdadero objeto de estudio, Cultura Corporal, cambiando así, Su papel pedagógico en el entorno escolar.

Palabras clave: Educación; Educación Física; Políticas públicas; Reformas educativas;

Abstract: This study aims to analyze the impacts of Law 13.415 and the Common National Curricular Base for the public teaching of Body Culture. In the light of Historical Dialectical Materialism, we carry out the dialogue between the political and educational conjuncture and Physical Education, relating them to the organization / reorganization of capital. We found that educational reforms again direct the school to meet the demands of the productive market, and place Physical Education in the area of Languages, which results in the loss of its true identity and its true object of study, Body Culture, thus changing, its pedagogical role in the school environment.

Keywords: Education; Education Physical; Educational Policies; Reforms Educational;

\section{Introdução}

Sucessivas reformulações, no contexto macroeconômico, caracterizam o período de reordenamento produtivo que vivenciamos no mundo imperialista contemporâneo. As políticas públicas, se constituem como produtos desse processo, a partir de um complexo campo de propensões políticas e econômicas, visando colocá-las em sintonia com os interesses hegemônicos do capital.

Nesse contexto globalizado, os organismos internacionais possuem a incumbência de formular e difundir as orientações necessárias para os diferentes países, adequando-os às mudanças do capital, 
oferecendo financiamento de projetos e reformas apontadas como indispensáveis para o progresso econômico (MAUÉS, 2003).

No contexto educacional, as condicionantes se intensificaram a partir de 1990, com a realização da Conferência Mundial sobre Educação para Todos, em Jomtien, na qual acusado como prioridade questões como a ampliação da rede básica, melhoria dos resultados de aprendizagem e a redução da taxa de analfabetismo.

Como primeiro desdobramento no Brasil, a Lei de Diretrizes e Bases n 9.394/96 (LDB/96) procurou ir ao encontro das expectativas do mundo globalizado, apresentando uma mudança no paradigma educacional, implicando mudanças na gestão e na prática cotidiana das instituições escolares. No mesmo movimento, Saviani (2018) demonstra as principais políticas educacionais realizadas no último período, partindo de Fernando Henrique Cardoso (1995-2002), com promulgação da LDB/96, do Fundo de Manutenção e Desenvolvimento do Ensino Fundamental e de Valorização do Magistério (FUNDEF) e do projeto do Plano Nacional de Educação (PNE), passando por Luiz Inácio Lula da Silva (2003-2010), autor do Fundo de Manutenção e Desenvolvimento da Educação Básica e de Valorização dos Profissionais da Educação (FUNDEB) e do Plano de Desenvolvimento da Educação (PDE), bem como por Dilma Vana Rousseff (2011-2016) que elaborou o Programa Nacional de Acesso ao Ensino Técnico e Emprego (PRONATEC) e o novo PNE, chegando até Michel Miguel Elias Temer Lulia (2016-2018) que por medida provisória implementou a Lei no 13.415 (Reforma Curricular do Ensino Médio).

Nesse contexto, nos questionamos: quais são os principais impactos das recentes reformas educacionais para o ensino público da Cultura Corporal? A partir desta problemática objetivamos analisar as concepções educacionais embutidas pela Lei $n^{\circ} 13.415$ e pela Base Nacional Comum Curricular (BNCC) para o ensino da Educação Física (EF) no ambiente escolar. Para tanto, em um primeiro momento, iremos expor a conjuntura política da educação brasileira, seguido da apresentação dos principais pontos propostos pelas normativas, para então, apresentar a discussão dos possíveis impactos das políticas educacionais na formação oferecida à população, e, em específico, no que se refere à área de conhecimento da EF.

Como referencial teórico, faremos uso do materialismo histórico dialético, que, segundo Marx (2008), parte da representação caótica do todo e, por meio da determinação mais estrita- refletida, possibilita chegar aos conceitos simples deste concreto e ao regressar inversamente ao concreto, esse apresenta ricas determinações e conceitos.

\section{Conjuntura política para a educação brasileira}

Como ponto de partida, se faz necessário discorrer sobre o momento sócio-histórico que estamos passando, pois as mudanças realizadas no âmbito educacional brasileiro, estão imbricadas ao processo macroeconômico do sistema capitalista.

Segundo Gentili (2007, p. 230), “o neoliberalismo expressa uma saída política, econômica, jurídica e cultural específica para a crise hegemônica que começa atravessar a economia do mundo 
capitalista como produto do esgotamento do regime de acumulação fordista". Tal vertente contrapôs as ideias até então hegemônicas no seio social, passando a difundir princípios diferentes ao modelo anterior. Para tanto, os ideais neoliberais, num primeiro plano apontaram para o combate ao Estado bem-estar social $^{3}$, promovendo a privatização de empresas estatais e de serviços públicos, além de desregulamentar as atividades econômicas, diminuindo, assim, a interferência dos poderes públicos sobre os empreendimentos privados. (MORAES, 2001).

No plano internacional, o neoliberalismo avançou no processo de desmantelamento dos estados-nacionais, preconizados pelo modelo Keynesianista e sua forte regulação, transferindo essas decisões para uma esfera global (Banco Mundial, Fundo Monetário internacional, entre outros). Isso criou novos ambientes de gestão das políticas regulatórias voltadas as nações do mundo globalizado (MORAES, 2001).

Segundo Bianchetti (2001, p. 108), “os capitais financeiros internacionais e o capital monopolista constituem, desde a década de 70, os novos grupos econômicos hegemônicos, que pretendem impor seu modelo de acumulação, através dos organismos internacionais”. Contudo, é a partir dos anos 80 que o projeto neoliberal começa a ser aplicado na prática em países desenvolvidos (Alemanha, Estados Unidos, Inglaterra) e, posteriormente, esse "receituário" se alastra para os demais países do globo. No Brasil, esse processo inicia no final dos anos 80, período concomitante com o processo de redemocratização civil. A política adotada no período obedeceu aos padrões internacionais, concretizando, assim, a redução do aparato estatal (através das privatizações) e oferecendo maior liberdade de mercado através das desregulamentações na área econômica.

$\mathrm{Na}$ contramão, a educação, já compreendida como medida compensatória ao sistema brutal inerente ao capitalismo, aumenta a oferta de matrículas na rede básica e atinge grande parcela da população brasileira. Para Basso; Neto (2014), a expansão educacional sob a lógica neoliberal dissemina a formação mínima, que instrumentaliza a maior parte dos trabalhadores e especializa parte dela para suprir as necessidades produtivas e, paralelamente, a elite, que abrigada no sistema privado, acessa a cargas pesadas de conhecimentos/conteúdos.

Nesse sentido, as políticas adotadas nas últimas décadas, apoiadas nas metas traçadas pelos organismos internacionais, resultaram em diferentes programas implementados no país, com objetivo de reduzir custos, otimizar resultados (melhora de indicadores em avaliações externas), além de reduzir os índices de analfabetismo e propiciar maior acesso à escola (BASSO; NETO, 2014). As reformas educacionais buscaram o alinhamento com o sistema globalizado, fazendo parte do mesmo pacote neoliberal dos ajustes fiscais realizados nos últimos anos, que segundo Beltrão (2019) buscaram responder uma questão simples: como a educação poderia contribuir na produtividade capitalista?

$\mathrm{Na}$ sociedade do livre mercado, o neoliberalismo, portanto, estabelece a educação como uma das prioridades do reordenamento capitalista para a volta do crescimento econômico dos diferentes países. A educação passa a ser um determinante importante nesse "novo" mercado, tornando-o mais competitivo e possibilitando que entidades/iniciativas privadas atuam no cenário global em torno da mercantilização desse direito social, que até então era dirigido, mantido e financiado, majoritariamente, pelo ente estatal. Germinal: Marxismo e Educação em Debate, Salvador, v. 12, n. 1, p. 390-400, abr. 2020. ISSN: 2175-5604 391 
A disputa histórica pela pauta educacional, demonstra os interesses divergentes entre os grupos sociais que almejam contemplar as suas necessidades básicas nas novas reformulações. No caso brasileiro, Martins (2013, p. 3) entende que os "grupos empresariais valendo-se da possibilidade da reconfiguração do espaço público e, a partir de sua condição de sujeitos da sociedade civil, cada vez mais ganham espaço na participação dos processos de mudanças das políticas sociais”.

Ao verificar o processo de reformulação educacional ocorrido nos EUA nas últimas décadas, Freitas (2018) relata que os reformadores operavam em redes difusas de influência com as presenças de acadêmicos, empresários, institutos, mídias, políticos, rentistas, entre outros. O movimento Todos pela Educação (TPE), é o exemplo brasileiro mais latente dessas redes, tendo por objetivo "criar senso de urgência, produzir conhecimento técnico, qualificar o debate público educacional e influenciar políticas públicas educacionais, para o avanço de aprendizagem aconteça"4. Vale ressaltar que estas redes difusas mantem afinidade/coerência com as diretrizes/metas dos grandes organismos internacionais, agindo sob a prerrogativa de serem representantes de todos, defensores do bem comum, apartidários e plurais, tendo por objetivo atuar pela educação de qualidade para toda a população (BELTRÃO, 2019).

Estes movimentos, no Brasil, ganham força nos governos petistas, colocando tais entidades/conglomerações em espaços de decisões políticas ativamente. De fato, é uma constatação assertiva dentro da história da política educacional brasileira a interferência desses setores na formulação de propostas educacionais (ANTUNES; PINTO, 2017). Entretanto, a novidade recente na atuação desses setores ocorre "através do fortalecimento de uma proposta de atuação nacional que conjuga o empresariado, o Estado e a sociedade civil através de um 'pacto' para reorganização do conjunto do sistema educativo público" (MARTINS, 2013 p. 30).

Em estudo, realizado por Bernardi; Uczak; Rossi (2018, p. 47), é apresentado a relação das cinco metas do movimento TPE 5 e as leis promulgadas durante a última década, confirmando a adesão das diretrizes/metas por parte das autoridades governamentais, o que demonstra "o imbricamento no discurso, nas relações e nas ações, mesmo [...] que o conteúdo da proposta do TPE sempre favorece o mercado e sua lógica própria, assim como a naturalização das parcerias privadas no setor público”. Assim, a nova "governabilidade" educacional garante a implementação de reformas educacionais, a partir das competências e habilidades básicas necessárias para a atividade econômica balizadas nas novas tecnologias (Revolução 4.0) e, também, auxilia, no movimento de retirar a educação do âmbito do "direito social" e inseri-la como "serviço" no interior do livre mercado, concepção coerente com a visão de sociedade e de Estado das referidas entidades (FREITAS, 2018, p. 41-42).

Por fim, segundo Caetano (2018), as políticas neoliberais visam implementar reformas na gestão pública e introdução da gestão gerencial, que combinadas à difícil situação financeira de alguns estados, à limitação anual de despesas obrigatórias (inclusive na educação pública) em decorrência do regime de recuperação fiscal (BASSI, 2018) e às políticas de austeridade como a emenda constitucional $\mathrm{n}^{\circ} 95^{6}$, que institui o novo regime fiscal das contas públicas da união por vinte anos (BRASIL, 2016), materializam a veracidade dos ataques contemporâneos aos direitos sociais. 


\section{A materialidade da reforma do ensino médio público}

No cenário político/econômico apresentado, que as novas propostas educacionais tomam como diretrizes curriculares a pedagogia das competências (PC), ou ainda, o aprender a aprender ${ }^{7}$ defendendo para a educação, um currículo por competências essenciais (letramento e numerização), competências transversais (comunicação, espirito de equipe, empreendedorismo, informática) e responsabilidade cívica e cidadã (UNESCO, 2008).

Dentro dessa ótica, a Lei n ${ }^{\circ} 13.415$ promove a reestruturação curricular do ensino médio, amplia a carga horária para 1000 horas anuais (até 2022) e flexibiliza o currículo para comportar a BNCC e a oferta de diferentes itinerários formativos (BRASIL, S/D ${ }^{8}$ ).

Entretanto, a organização por itinerários desencadeia imensas mudanças no percurso formativo secundário. Inicialmente, ocasiona a hierarquização de componentes curriculares ao garantir apenas o ensino de português e matemática nos três anos do referido nível de ensino (BRASIL, 2017). Também demanda a flexibilização do tempo destinado aos conteúdos, uma vez que são destinados $60 \%$ (1800 horas) para os conteúdos comuns da BNCC e 40\% (1200 horas) para os Itinerários Formativos. E, por fim, a organização curricular apresenta cinco áreas: Linguagens e suas tecnologias; Matemática e suas tecnologias; Ciências da natureza e suas tecnologias; Ciências humanas e sociais aplicadas; Formação técnica e profissional (BRASIL, 2017).

Com a presença do marco regulatório, a BNCC implementa os novos ideais educacionais, subtraindo o "excesso" de componentes curriculares e abordagens pedagógicas do ensino médio que se afastam do mundo do trabalho e das questões sociais contemporâneas (BRASIL, 2018a). Para tanto, a BNCC idealiza que as experiências favoreçam a preparação básica para o trabalho e para a cidadania, por meio do desenvolvimento de competências, possibilitando aos estudantes a inserção ativa, crítica, criativa e responsável no mundo do trabalho, cada vez mais complexo e imprevisível, preparando-os assim, para as novas condições de ocupação ou aperfeiçoamento posteriores (BRASIL, 2018a).

Discordando de tal modelo, que focaliza na flexibilização do currículo e dos conhecimentos, Martineli et al. (2016), afirma que normatizações dessa proporção deveriam almejar um processo educacional que contribua para o desenvolvimento pleno das capacidades humanas, para formar um sujeito capaz de compreender a realidade social e suas respectivas contradições. Já Martins (2004, p. 68), defende que a função da escola é a socialização do saber historicamente produzido, objetivando a máxima socialização dos indivíduos, por meio da condição explicativa dos conhecimentos clássicos entre as gerações, que possibilita "o estabelecimento de relações causais inteligíveis sobre os fenômenos, na base dos quais esta realidade passa a ser conhecida, compreendida e problematiza em sua essência".

Distante desse entendimento, o "novo" modelo educacional, embasado na PC vincula-se a visão do livre mercado, que necessita do trabalho flexível, instável e precário, delegando à formação básica, o ensino dos conhecimentos "essenciais" e desenvolvimento das habilidades e competências úteis para a lógica da empregabilidade, que, com o avanço tecnológico, alcançou a condição de substituir trabalhadores por avançadas máquinas (robótica) em suas linhas de montagem. Assim, a equação final desse processo 
resulta num número limitado de postos de trabalho "reservado" aos indivíduos mais competentes (ANTUNES; PINTO, 2017).

Para a concretização da proposta, a Unesco (2008) enfatiza a importância das parcerias entre os setores público e privado na implementação das políticas educacionais. Em vista disso, tais parcerias público-privadas poderiam ser a "saída privatista” pelo Estado para oferta dos itinerários formativos, que se apresentam como uma incógnita nas redes públicas. Essa incógnita faz parte de uma série de dificuldades, como a disponibilidade real de estrutura adequada, os recursos materiais e humanos para sta implementação da reforma no ensino público.

Por fim, a BNCC e Lei $n^{\circ} 13.415$ utilizam em seu discurso, a possibilidade de os jovens construírem seus projetos de vida e formativos (BRASIL, 2017), além do respeito ao seu protagonismo estudantil em sua aprendizagem (BRASIL, 2018a), mas, negligenciam ao não expor as consequências subsequentes da escolha por um "caminho formativo". Os resultados da flexibilização é são o esvaziamento escolar, a perda de apropriação dos conhecimentos e o distanciamento do ensino superior por parte dos alunos (BARBOSA, 2019).

Em suma, a reforma do ensino médio (REM ${ }^{9}$ ) expressa as seguintes características para a educação: 1) Propicia uma formação cada vez mais voltada para o mercado produtivo; 2) Abre possibilidade para criação de parcerias (com entidades privadas) para atender a parcela diversificada do currículo; 3) O “não" acesso a todos os conhecimentos afasta os estudantes do ensino superior; 4) Perda de acesso à totalidade do conhecimento; 5) O viés do aprender a aprender visa a naturalização da lógica da empregabilidade do sistema mercantil do novo século.

\section{Educação Física e o ensino público da cultura corporal}

A REM, ao adotar a flexibilidade como princípio de organização curricular (BRASIL, 2018a), passa a organizar o currículo em áreas de conhecimentos, promovendo a generalização do conhecimento dentro delas. $\mathrm{Na}$ especificidade da EF, a disciplina é deslocada à área das Linguagens e suas tecnologias, junto aos conhecimentos de Artes, Língua Estrangeira, Literatura e Língua Portuguesa.

Neste sentido, a resolução 03/2018 do Conselho Nacional de Educação, que atualiza as diretrizes curriculares nacionais para o ensino médio, normatiza que o currículo deve ser organizado e planejado dentro das áreas de forma interdisciplinar e transdisciplinar (BRASIL, 2018b). Ao adotar esse modelo de organização, as generalizações nas áreas de conhecimento ocorrem inevitavelmente, visto que, seus objetos de estudos não atendem as especificidades de cada componente curricular, resultando em objetivos gerais e superficiais do conhecimento historicamente construído.

$\mathrm{Na}$ área das Linguagens e suas tecnologias, a BNCC entende como objetos das diversas disciplinas as linguagens artísticas, corporais e verbais (oral ou visual-motora, como Libras e escrita) tendo como responsabilidade a promoção de oportunidades para a consolidação e ampliação das habilidades de uso e de reflexão. Já EF, por meio das experiências em torno de seus conteúdos, deve desenvolver o autoconhecimento e o autocuidado com o corpo e a saúde, a socialização, o entretenimento e ampliar o 
entendimento a respeito dos fenômenos da gestualidade e das dinâmicas sociais associadas às práticas corporais (BRASIL, 2018a).

A partir deste cenário "divulgado" pela BNCC, levantamos duas proposições sobre a especificidade da EF: a) qual o objeto de estudo da EF? e b) qual o papel da EF na formação escolar?

a) Qual o objeto de estudo da EF? Essa pergunta se torna indispensável, visto que o conteúdo contido na BNCC para a EF se distancia dos debates e acúmulos obtidos dentro da área nas últimas décadas em que esse processo se intensificou. Corroborando Souza e Ramos (2017 p. 77), que caracterizam esse momento histórico como “de intensas descobertas para a área, visto que, além de colocar em questionamento o que se refere à hegemonia biologista, possibilitou uma intensa produção teórica e a construção de um novo paradigma”.

A necessidade de questionar o objeto de estudo, advém do equívoco de alocar a EF dentro da área das Linguagens e suas tecnologias, sob justificativa de que a preocupação do componente curricular é a linguagem, em especial a corporal, por meio da compreensão dos fenômenos da gestualidade e práticas corporais por parte dos estudantes.

Contrariamente à definição da BNCC, de aplicar a linguagem como categoria central do ensino, compreendemos que a categoria central de toda vida humana e por consequência do processo educativo é o trabalho, atividade essencial para vida humana e em sociedade.

Em uma passagem, sobre o processo histórico da transformação do macaco em homem, Engels (2004) observa que as possibilidades e destrezas adquiridas pela mão humana é produto da adaptação e transmissão entre gerações pelo trabalho. Logo, podemos pensar que a própria linguagem também é fruto do trabalho, bem como, de todas as atividades corporais como os jogos, o esporte, a ginástica, entre outras.

Colaborando com essa visão, Taffarel (2012, p. 163) afirma que,

As relações entre atividade física - Educação Física - cultura corporal são uma construção sócio-histórica que depende do modo de vida, do modo de organizar a produção dos bens materiais e imateriais e isto não pode ser visto isolado a partir de um indivíduo, e muito menos a partir de uma representação, a linguagem, mas, sim, tem que ser encarado historicamente, a partir da totalidade da espécie humana, do gênero humano, a partir da lutas de classe. Por isso não podemos abstrair das práticas corporais seus sentidos e significados, ou seja, seu conteúdo histórico.

Ela ainda afirma que,

O homem não nasceu praticando esporte, muito menos relacionando esporte com saúde, mas adquiriu, pelo trabalho, pelas atividades, as condições de produzir e reproduzir seu modo de vida onde as relações entre esporte e saúde foram se consolidando. Essa construção passa pelas relações do homem com a natureza e com os outros homens na manutenção da vida humana. Aí se constrói a cultura corporal jogos, esporte, dança, ginástica, lutas e outras formas que tratamos pedagogicamente na escola.

Em consonância, Escobar (2012) alega que o homem constrói/transforma o mundo a partir do trabalho. Tal categoria (Trabalho) é uma explicação do que o homem faz, indicando que o homem "age" sobre a realidade concreta. Dessa forma, ao longo da própria história, o homem criou entre outras coisas, os jogos, que também se relacionavam ao trabalho, tendo por objetivo sua resignação em atividade lúdica. 
Por esse viés, o ensino na EF visa a totalidade do conhecimento, embutindo-o as questões históricas, filosóficas, epistemológicas e sociais inerentes às suas manifestações, sejam elas esportivas, folclóricas, rítmicas oriundas do processo de mudanças sócio-históricas do mundo dos homens, ou seja, do trabalho.

A Cultura Corporal, através dos diferentes temas que a compõem, "expressam um sentido/significado onde se interpenetram, dialeticamente, a intencionalidade/objetivos do homem e as intenções/objetivos da sociedade” (SOARES, et al., 2012, p. 62). Portanto, as relações entre os jogos, esportes, ginástica, lutas e danças também correspondem aos determinantes sociopolíticos inerentes a sua condição de produto histórico humano, que, por consequência, pode manifestar diferentes interesses, a partir de sua apropriação ou não por parte das classes sociais.

Entretanto, recentemente, é possível constatar a crescente utilização da linguagem corporal como objeto do ensino nas aulas de EF nas escolas, restringindo a produção e reprodução das diferentes expressões corporais a elas mesmas. Assim, os jogos, os esportes, as danças, e os demais conteúdos não se conectam com suas construções históricas e sociais, mas se relacionam apenas entre o sujeito (jogador/praticante) e objeto (jogo/esporte/dança), são apenas representações a serem experienciadas e que poderão ser utilizadas como meios de comunicação entre o sujeito e os demais.

Impregnada por uma perspectiva reducionista e individualista do conhecimento, a EF passa ser uma mera promotora de vivências nas diferentes possibilidades da linguagem corporal, a fim de que seu resultado seja o desenvolvimento de competências, a partir da consolidação de um conjunto de habilidades. Não por acaso, a BNCC se estrutura na relação imediata entre essas duas dimensões, como se o processo de ensino resumisse, mecanicamente, à transformação de uma, em outra.

Essa dualidade de percepções, perante ao trabalho da EF no ambiente escolar, nos demanda a utilização da segunda questão levantada anteriormente em nosso estudo, visto que ambas percepções apontam para diferentes lados.

b) Qual o papel da EF na formação escolar? Ao longo do seu desenvolvimento histórico, a EF no ambiente escolar desempenhou diferentes papeis, forjando o corpo (objeto) para os respectivos modelos de trabalho reproduzidos historicamente no seio social.

Inicialmente, na virada do século XVIII para o XIX (período da revolução industrial) na Europa, coube a EF servir de meio educativo, a partir de seu conteúdo médico-higienista, visando disciplinar o corpo biológico para a nova ordem burguesa, adotando novos hábitos, atitudes e saberes. Ainda durante o século XIX, o mesmo corpo passa a ser compreendido como peça "essencial” do modelo de produção, exigindo-o um vigor físico para o avanço do capital. Logo, a EF amplia a visão perante ao corpo biológico, compreendendo-o também como corpo social, direcionando políticas educacionais para o ensino de expressões higienista e sanitarista para os trabalhadores (SOARES, 2012).

Ainda segundo a autora, a EF chega ao Brasil já no final do século XIX, nas instituições militares inicialmente e, a posteriori, nos ambientes escolares. A "higiene, raça, moral pontuavam as propostas pedagógicas e legais que contemplam a EF, e as funções a serem por ela desempenhadas não poderiam ser outras senão as higiênicas, eugênicas e morais" (SOARES, 2012, p. 76). Germinal: Marxismo e Educação em Debate, Salvador, v. 12, n. 1, p. 390-400, abr. 2020. ISSN: 2175-5604 
A primeira grande mudança dentro do desenvolvimento da EF ocorre devido à alteração do seu conteúdo hegemônico, passando dos modelos ginásticos para o esportivo. Esse processo, comumente denominado de esportivização da EF, encontrou respaldo nos movimentos sociopolíticos do sistema capitalista, colocando a possibilidade de engendramento de políticas governamentais que vincularam a EF ao sistema esportivo (RODRIGUES; BRACHT, 2010).

Segundo Lima (2012), na década de 70, a EF ganhou prestígio para a manutenção da ordem e do progresso, investindo em diretrizes pautadas no nacionalismo, na integração nacional (entre os Estados) e na segurança nacional. Ela considerava as atividades esportivas como fatores colaborativos na melhoria da força de trabalho para o milagre econômico brasileiro.

Só na década de 80, ocorreu a principal mudança do desenvolvimento histórico da área da EF: o movimento renovador. Esse movimento provocou a ruptura do paradigma até então hegemônico, a aptidão física (esportivização/comportamentalismo). Esse processo, também é fruto do período de redemocratização do país e possibilitou saltos qualitativos para a área, resultando em diferentes sistematizações (abordagens) para o ensino da disciplina no ambiente escolar.

É dessa materialidade histórica, que se constituíram os alicerces da EF Escolar. A compreensão na totalidade do processo expõe a relação com os interesses sociais hegemônicos. Da mesma forma, o atual processo político/pedagógico que pretende colocar a EF na área das Linguagens e suas tecnologias objetiva perpetuar as influências do passado, incumbindo o corpo como objeto de estudo, a partir da PC, submetendo assim, o ensino da EF às demandas do mundo do trabalho contemporâneo.

$\mathrm{Na}$ contramão, entendemos que a EF a partir da Cultura Corporal, deve estar presente no ambiente escolar, comprometida com suas bases históricas e sociais, que considera o homem enquanto produtor de cultura, inclusive a corporal, e transmissor desses conhecimentos integrantes do patrimônio cultural humano que através do trato pedagógico dos conhecimentos podem fornecer elementos das diferentes práticas sociais objetivadas no processo histórico da existência humana em sua totalidade (SOUZA, 2009).

$\mathrm{Na}$ essência, as novas políticas educacionais, oferecem uma pequena parcela dessa totalidade. A apropriação dos conhecimentos mais refinados que a humanidade conseguiu sistematizar até a atualidade passa longe de ser a prioridade, propondo o ensino "flexível" de conhecimentos simplistas dentro das diferentes áreas, com propósito de desenvolver competências e habilidades ditas necessárias. Segundo Antunes; Pinto (2017, p. 104), essa nova educação da sociedade do mercado prioriza "uma formação volátil, superficial e adestrada para suprir as necessidades do mercado de trabalho 'polivalente', 'multifuncional' e flexível'.

Para tanto, a EF passa por um período de esvaziamento de significados dentro da REM, visto que sua intervenção pedagógica no ambiente escolar não corresponde aos novos traços do trabalhador do século XXI. Se, anteriormente, se fazia necessária a educação higiênica, posteriormente a necessidade de corpos fortes para desempenhar funções predominantemente braçais, hoje recrutam-se propriedades intelectuais e de socialização dos indivíduos. Nesse viés, do mercado de trabalho, se justifica uma formação que rebaixa componentes curriculares como a EF, Artes, Sociologia e Filosofia. Contudo, no Germinal: Marxismo e Educação em Debate, Salvador, v. 12, n. 1, p. 390-400, abr. 2020. ISSN: 2175-5604 397 
entendimento de Souza; Ramos (2017), os conteúdos da EF, na visão pós-moderna das competências, ainda podem contribuir para moldar a personalidade (responsabilidade, iniciativa, comunicação, etc.) dos trabalhadores. Almeja-se que esses consigam responder positivamente à dinâmica do livre mercado contemporâneo.

\section{Considerações finais}

A partir da análise realizada ao longo desse estudo, entendemos que REM é parte da readequação da rede produtiva contemporânea. Nesse sentido, priorizam-se, no perfil formativo secundário, os conhecimentos técnicos e superficiais, em detrimento da apropriação dos conhecimentos científicos historicamente construídos e sistematizados nos diferentes componentes curriculares. Por consequência, acaba-se afastando os alunos/trabalhadores da possibilidade de acesso ao ensino superior.

Portanto, a escola embasada na PC, tem a centralidade de desenvolver as habilidades "modernas", voltadas para a submissão de seus alunos/trabalhadores ao mercado de trabalho moderno. Percebe-se também, a aproximação do sistema secundário ao mercado, através da possibilidade de implementação de parcerias público-privadas para a complementação dos itinerários formativos.

No plano específico da EF, os ataques também ocorrem de formas distintas, inicialmente por "excluir" o componente curricular dentro do novo currículo, colocando-a como prática e estudos no cenário curricular do ensino médio. E depois por alocar a disciplina dentro da área das Linguagens e suas tecnologias, que resulta na perda de sua verdadeira identidade e de seu verdadeiro objeto de estudo, a Cultura Corporal, alterando assim, seu papel pedagógico no ambiente escolar.

Tendo em vista as limitações do presente estudo, objetivamos ao máximo contribuir com o debate do momento histórico atual. Compreendemos que uma verdadeira mudança é necessária para adequar a educação, mas diferentemente das últimas proposições realizadas, essa mudança deve realmente estar balizada pelos interesses dos sujeitos históricos, a classe trabalhadora. Ansiamos que a nova formulação da EF escolar aponte para um modelo social diferente aos que está colocado a nós.

\section{Referências bibliográficas}

ANTUNES R; PINTO G. A. A fábrica da educação: da especialização taylorista à flexibilização toyotista. São Paulo: Cortez, 2017.

BARBOSA, C. S. O novo ensino de tempo integral: reducionismo, privatização e mercantilização da educação pública em tempos de ultraconservadorismo. Revista Multidisciplinar de Ensino, Extensão e Cultura do Instituto de Aplicação Rodrigues da Silveira (CAp-UERJ), v. 8, n. 19, p. 94-107, set./dez. 2019.

BASSI, C. M. Implicações dos novos regimes fiscais no financiamento da educação pública. Textos para discussão/ Instituo de Pesquisa Econômica Aplicada - Brasília: Rio de Janeiro: Ipea, 2018.

BASSO, D. J; NETO, L. B. As influências do neoliberalismo na educação brasileira: algumas considerações. Revista Eletrônica do Curso de Pedagogia do Campus Jataí -UFG, v.1, n.16, p. 1-15, jan./jun. 2014. 
BELTRÃO, J. A. Novo ensino médio: rebaixamento da formação, o avanço da privatização e a necessidade de alternativa pedagógica crítica na educação física. 2019. 267p. Tese (Doutorado em Educação) - Universidade Federal da Bahia, Salvador, 2019.

BERNARDI, L. M; UCZAK, L. H; ROSSI, A. J. Relações do movimento empresarial na política educacional brasileira: a discussão da Base Nacional Comum. Currículo sem Fronteiras, v.18, n.1, p. 29 51, jan./abr. 2018.

BIANCHETTI, R. G. Modelo Neoliberal e Políticas Educacionais. 3. ed. São Paulo: Editora Cortez, 2001.

BRASIL. Base Nacional Comum Curricular. Educação é Base. MEC: Brasília, 2018a. Disponível em: http://basenacionalcomum.mec.gov.br/abase/. Acesso em: 09 ago. 2019.

BRASIL. Emenda Constitucional No 95 de 15 de dezembro de 2016. Altera o Ato das Disposições Constitucionais Transitórias, para instituir o Novo Regime Fiscal, e dá outras providências. In: Diário Oficial da República Federativa do Brasil, 16 de dezembro de 2016. Disponível em: http://pesquisa.in.gov.br/imprensa/jsp/visualiza/index.jsp?jornal=1\&pagina=2\&data=16/12/2016. Acesso em: 30 abr. 2019.

BRASIL. Lei n $\mathrm{n}^{\mathrm{1}}$ 13.415, de 16 de fevereiro de 2017. Altera as Leis $\mathrm{n}^{\circ}$ 9.394, de 20 de dezembro de 1996 e 11.494, de 20 de junho de 2007, e a Consolidação das Leis do Trabalho - CLT. In: Diário Oficial da República Federativa do Brasil, 17 de fevereiro de 2017. Disponível em: http://pesquisa.in.gov.br/imprensa/jsp/visualiza/index.jsp?.jornal=1\&pagina=1\&data=17/02/2017. Acesso em: 15 abr. 2019.

BRASIL. Novo Ensino Médio - perguntas e respostas. In.: Portal MEC: Brasília, S/D. Disponível em: http://portal.mec.gov.br/component/content/article?id=40361. Acesso em: 15 mar. 2019.

BRASIL. Resolução No 3: Atualiza as Diretrizes Curriculares Nacionais para o Ensino Médio. MEC: Brasília, 2018b. Disponível em:

http://novoensinomedio.mec.gov.br/resources/downloads/pdf/dcnem.pdf. Acesso em: 30 jun. 2019.

CAETANO, M. R. A educação no contexto de crise do capital e as relações entre estado, mercado e terceiro setor nas políticas educacionais. Laplage em Revista, Sorocaba, v.4, n.2, p. 153-168, mai./ago. 2018.

ENGELS, F. Sobre o papel do trabalho na transformação do macaco em homem. In: ANTUNES, R. (org.). A Dialética do trabalho. - São Paulo: Expressão Popular, 2004.

ESCOBAR, M. Depoimento. In: SOARES, C. L. et al. Metodologia do ensino de educação física. $4^{\mathrm{a}}$ reimpr. da 2. ed. rev. São Paulo: Cortez, 2012.

FREITAS, L. C. A reforma educacional da educação: nova direita, velhas ideias. 1. ed. São Paulo: Expressão Popular, 2018.

GENTILI, P. A. A. Adeus à escola pública a desordem neoliberal, a violência do mercado e o destino da educação das maiorias. In: GENTILI, P. A. A. (Org.) Pedagogia da exclusão: crítica ao neoliberalismo em educação. 13. ed. Petrópolis: Vozes, 2007.

LIMA, R. R. Para compreender a história da Educação Física. Educação e Fronteiras On-line, Dourados, MS, v.2, n.5, p. 149-159, mai./ago. 2012.

MARTINELI, T. A. P. et al. A Educação Física na BNCC: concepções e fundamentos políticos e pedagógicos. Motrivivência, v.28, n.48, p.76-95, set. 2016.

MARTINS, E. M. Movimento “todos pela educação”: um projeto de nação para a educação brasileira. 2013. 184p. Dissertação (Mestrado em Educação) - Universidade Estadual de Campinas, Campinas, 2013.

MARTINS, L. M. Da formação humana em Marx à crítica da pedagogia das competências. In: DUARTE, N. (Org.). Crítica ao fetichismo da individualidade. Campinas, SP: Autores Associados, 2004.

MARX, K. Contribuição à crítica da economia política. Trad. Florestan Fernandes. 2 ed. São Paulo: Expressão Popular, 2008. 
MAUÉS, O. C. Reformas internacionais da educação e formação de professores. Cadernos de Pesquisa, n.118, p. $89-117$, mar. 2003.

MORAES, R. C. Neoliberalismo: de onde vem, para onde vai? São Paulo: Editoria SENAC, 2001.

RODRIGUES, L. L; BRACHT, V. As culturas da Educação Física. Revista Brasileira de Ciências do Esporte. v.32, n.1, p. 93-107, set. 2010.

SAVIANI, D. Política educacional no Brasil após a ditadura militar. HISTEDBR On-line, Campinas, v.18, n.2, p.291-304, 2018.

SOARES, C. L. Educação Física: raízes europeias e Brasil. 5. ed. rev. Campinas, SP: Autores Associados, 2012.

SOARES, C. L. et al. Metodologia do ensino de educação física. $4^{a}$ reimpr. da 2. ed. rev. São Paulo: Cortez, 2012.

SOUZA, M. S; RAMOS, F. K. Educação Física e o Mundo do trabalho: um diálogo com a atual reforma do Ensino Médio. Motrivivência, Florianópolis, v. 29, n. 52, p. 71-86, set. 2017.

SOUZA, M. S. Esporte Escolar: possibilidade superadora no plano da cultura corporal. São Paulo: Ícone Editora, 2009.

TAFFAREL, C. Depoimento. In: SOARES, C. L. et al. Metodologia do ensino de educação física. $4^{\mathrm{a}}$ reimpr. da 2. ed. rev. São Paulo: Cortez, 2012.

TODOS PELA EDUCAÇÂO. Quem Somos: Brasil, 2019. Disponível em: https://www.todospelaeducacao.org.br/pag/quem-somos/. Acesso em: 30 abr. 2019.

UNESCO. Declaração Mundial sobre Educação para Todos: satisfação das necessidades básicas de aprendizagem. Jomtien: UNESCO, 1990. Disponível em: https://unesdoc.unesco.org/ark:/48223/pf0000086291_por. Acesso em: 20 jul. 2019.

UNESCO. Reforma da educação secundária: rumo à convergência entre a aquisição de conhecimento e o desenvolvimento de habilidade. Brasília: UNESCO, 2008.

\section{Notas:}

1 Mestrando no Programa de Pós-Graduação em Educação Física. Universidade Federal de Santa Maria. CV: http://lattes.cnpq.br/8350441034783183 Orcid: https://orcid.org/0000-0002-7428-7855 email: gabrielvgef@gmail.com

2 Professora da Universidade Federal de Santa Maria, Departamento de Desportos Individuais. Membro do Grupo de Pesquisa em Lazer e Formação de Professores - UFSM - http://dgp.cnpq.br/dgp/espelhogrupo/4523 CV: http://lattes.cnpq.br/7685329921498975 Orcid: $\quad$ https://orcid.org/0000-0002-9624-3060 $\quad$ Email: maristeladasilvasouza@yahoo.com.br

${ }^{3} \mathrm{Na}$ visão política Keynesianista, apregoava-se a máxima intervenção do Estado na economia, fortalecendo as leis trabalhistas a fim de aumentar a potencialidade do mercado consumidor, o que contribuía para o escoamento das produções fabris.

4 Informação expressa no site oficial “todos pela educação". Disponível em: https://www.todospelaeducacao.org.br/pag/atuacao/\#bloco 64.

${ }^{5}$ Disponíveis em: https://www.todospelaeducacao.org.br/pag/dados-5-metas.

6 Normativa legal na integra em: http://pesquisa.in.gov.br/imprensa/jsp/visualiza/index.jsp?jornal=1\&pagina=2\&data=16/12/2016.

7 Disponível em: https://unesdoc.unesco.org/ark:/48223/pf0000109590 por.

8 Ler mais em: http://portal.mec.gov.br/publicacoes-para-professores/30000-uncategorised/40361-novo-ensinomedio-duvidas.

${ }^{9}$ A utilização da sigla no texto, vai expressar a totalidade das reformas estudadas, ou seja a Lei no 13.415 e BNCC do ensino médio. 